\title{
Challenges in doing participatory design with people with dementia
}

\author{
Niels Hendriks \\ Social Spaces | CUO \\ LUCA, KULeuven \\ Niels.hendriks@khlim.be
}

\author{
Liesbeth Huybrechts \\ Social Spaces | CUO \\ LUCA, KULeuven \\ Liesbeth.huybrechts@khlim.be
}

\author{
Andrea Wilkinson \\ Social Spaces | CUO, \\ LUCA, KULeuven \\ Andrea.wilkinson@khlim.be
}

\author{
Karin Slegers \\ CUO | Social Spaces, \\ Iminds, KULeuven \\ Karin.slegers@soc.kuleuven.be
}

\begin{abstract}
This paper critically looks at the role of people with dementia (and their network) when involved in a participatory design (PD) process and the role of designers when involving a person with dementia (and their network). Two participatory projects (ATOM and Dementia Lab) were analyzed and challenges in doing PD together with people with dementia are defined.
\end{abstract}

\section{Author Keywords}

People with dementia; participatory design

ACM Classification Keywords

H.5.2 User Interfaces

\section{INVOLVING PEOPLE WITH DEMENTIA IN RESEARCH AND DESIGN PROCESSES}

Dementia is an umbrella term used to describe a variety of psychiatric and cognitive symptoms. Personality changes, depression, hallucinations and delusions are the most known psychiatric symptoms. On a cognitive level people with dementia almost always suffer from a deterioration of memory (such as amnesia), difficulties in language (aphasia), the inability to perform purposeful movements (apraxia) and orientation in time and place (agnosia) (APA, 2000). Additional behavioral and cognitive problems (irritation/frustration, short attention span, an inability to learn new routines,...) can occur. As a large group of people with dementia belong to the group of older persons, physical ailments like impaired eyesight, hearing or physical coordination are likely to appear (Lobo et al., 1999). A wide variety of types of dementia exists and the way it affects daily life will be different for each person.

\section{Involvement in research and design}

To involve people with dementia in a research and design process is not an easy thing. In the domain of design of IT applications, Span et al. (2013) found that only 2 out of 26 research projects involved the person with dementia not as an object of study or informant, but as a partner (or

Permission to make digital or hard copies of all or part of this work for personal or classroom use is granted without fee provided that copies are not made or distributed for profit or commercial advantage and that copies bear this notice and the full citation on the first page. Copyrights for components of this work owned by others than ACM must be honored. Abstracting with credit is permitted. To copy otherwise, or republish, to post on servers or to redistribute to lists, requires prior specific permission and/or a fee. Request permissions from Permissions@acm.org.

PDC '14 Companion, October 06 - 10 2014, Windhoek, Namibia Copyright is held by the owner/author(s). Publication rights licensed to ACM.

ACM 978-1-4503-3214-9/14/10 _\$15.00

http://dx.doi.org/10.1145/2662155.2662196 co-designer) in the design and research process. To see the person with dementia as a mere object of study or to only rely on proxies stems from the vision on the person with dementia as the 'uncollected corpse' (Miller, 1990) or as someone who no longer possesses a sense of self. Kitwood (1997), however, states that a person with dementia must be recognized as a person with thoughts, emotions, wishes and thus, a person who should actively be included in research.

\section{Participatory design with people with dementia}

To actively include people with dementia in research and design can be done by using participatory design methods. Although we see good examples of working in a participatory manner with people with dementia (Holbø, et al., 2013; Lindsay, Brittain, et al., 2012; Mayer \& Zach, 2013; Meiland et al., 2012), the question we are trying to answer in this paper, is what the challenges experienced in doing PD with people with dementia in two projects were. We will look at the role of the participants (person with dementia, designer,...), the analysis and the scalability of the research results and the impact of the PD process on the participants.

\section{CHALLENGES OF DOING PARTICIPATORY DESIGN WITH PEOPLE WITH DEMENTIA}

We define 7 challenges in doing PD with people with dementia coming from our experience in two projects. The challenges can be seen as a result of so-called thick descriptions (Ponterotto, 2006) in the way that central to them is the interpretation of what has been observed, perceived and experienced.

The two projects involved are ATOM \& Dementia Lab:

-ATOM was a 2-year project researching the creation of an intelligent network of objects and people to ameliorate the life of people with dementia. Different participatory design trajectories with persons with dementia, family, caregivers and designers were set up. The result was a sensor based app supporting wellbeing during mealtime.

-The Dementia Lab is a 1-year project researching how to design and share low-tech solutions in participatory ways to make the life of people with dementia, their caregivers, partners and family more pleasant. The designs resulting from the Dementia Lab vary from extensions to walkers, over coloring books for people with dementia or visual cutting plates for cooking.

The 7 challenges seem to come down to 3 fundamental concerns: the lack of an approach for PD with people with dementia which goes beyond a single case; the overappreciation of the visual and the verbal; and the perception of PD. 
Engaging in long-term PD research with people with dementia could contribute to a renewed view on approaching it. Little research on PD and dementia goes beyond single case studies. Without a body of literature describing more than almost anecdotic tips on doing PD with people with dementia, it is difficult to achieve a broader vision on doing PD with people with dementia.

The perception of what participatory design is, comes from how PD has traditionally been defined. Most visions on PD date back to the early tradition of the Scandinavian legacy of PD where partners of (relatively) equal cognitive and physical abilities participated in the PD sessions. Grönvall \& Kyng (2011) refer to the way early PD projects still shape the way PD is set up, focusing strongly on PD within a professional context combining lay and professional workers who are able to communicate, visualise, make abstractions,... People with dementia lack this ability to communicate verbally (due to aphasia), having a hard time to work in a visual manner or make abstractions. Related to this is the overvalued appreciation of the visual and the verbal. Jones et al. (2006) link this to the modernist order of art in relation to the senses: "sculpture was denigrated because of its proximity to touch; painting celebrated for its appeal to sight (a more abstract and cerebral sense)".

We are aware of potential points of critique to the 7 challenges we will articulate: other researchers, designers or project setups might have a different perspective on the challenges raised. The first point of critique might be related to the fact that we formulated the challenges as statements (rather than questions). We do that because they state the personal experience of the designers and researchers involved. Nevertheless, all challenges are framed in a broader context, since, when possible, they are linked to existing literature raising the same or similar issues. A second point of critique might be related to the fact that the challenges are not exclusively linked to participatory design together with people with dementia. They might apply to PD with other weak users, or to an even larger group of participants. We see it as valuable that learning from one group can bring experience and knowledge for working with other groups in society.

\section{The cognitive limitations of a person with dementia may make PD too difficult}

As part of our PD process in the ATOM-project we made use of a set of stickers and a map to visualize the life of the persons with dementia. This map created an opportunity to make specific the potential problems that arise due to the symptoms of dementia. The method used was an adapted version of the participatory method MAPit (Schepers, 2013). MAP-it was adapted taking into account the nature of the condition of dementia by, for example, combining visual with textual cues, focusing on small and separated assignments,... in order to overcome, amongst others, memory problems. In the mapping process, we integrated the character of a 'Mr Fixit' to playfully discuss how to overcome the issues the person with dementia is facing and tried to visualize - with the aid of a designer - possible solutions.
During the mapping session, the impairments of the people with dementia seemed to surface especially when (even a minor form of) abstraction was needed. The capability of understanding a fantasy item (Mr. Fixit) seemed to be a problem. Making a choice from a limited set of options was frustrating to the people with dementia even when the choices were - to us- quite simple, such as what color out of a set of colors should we pick.

Understanding the design task, knowing what to do next and keeping the person with dementia on track became a continuous action.

The visual way of working seemed to cause problems as well: the icon stickers were sometimes not understood or were hard to relate with. In the first session the researcher and designer brought pens, markers and blank icon stickers to encourage the person with dementia to create their own icon stickers or emphasize elements of the map. This seemed to be too ambitious as no person with dementia was eager to create or adapt stickers.

Though we were aware of the lack of initiative (APA, 2000) that most of the persons with dementia face, we were still struck by how little 'action' was taken by the persons with dementia themselves: icon stickers had to be torn off by the designer or the family member; small segments of the research question had to be repeated repeatedly. Moreover, all of the participants of the ATOM project relied heavily on the accompanying trusted family member even in such a way causing irritation with one of the participating family members.

To conclude, we see difficulties in making abstractions and the visual way of working commonly used in PD. Also, people with dementia experienced problems in making a choice, understanding assignments or staying on track. Moreover, a general passivity and a strong reliance on a trusted family member were noted

\section{The results of PD sessions are difficult to be translated to the wide variety of forms of dementia}

The question of scalability might be an issue for each form of participatory design and qualitative research in general (Lewis \& Ritchie, 2003), but it might be even more a challenge when working with people with dementia. As indicated, dementia is an umbrella term encompassing a wide variety of psychiatric and cognitive symptoms. Though generalization is possible, we see that the dementia process is an individual and unpredictable process: one participant might be able to communicate verbally while others suffer heavily from aphasia.

Moreover, we notice that most design projects involve people with mild to moderate forms of dementia. The projects Span et al. (2013) researched, involved a majority of people with mild dementia. People with moderate dementia participated mostly in heterogeneous groups mixed with people with mild dementia. Span et al. see no research involving people with severe dementia. Also, in our projects, we worked with people with mild to moderate forms of dementia, since the PD sessions demanded some form of self-awareness.

If research and design projects only focus on mild and moderate dementia and dementia is generalized, is it then 
possible to 'translate' the outcomes of PD sessions to a larger user group and if so, how?

\section{It is unclear whether the people with dementia, their caregivers and relatives are reliable}

In her study, Meiland et al. (2012) doubts the reliability of her user group of people with dementia "especially when they were asked to give an opinion regarding their experiences over a longer period of time". Also in our own research stories of long deceased relatives visiting or an overestimation of one's own capacities were quite common. This was, however, not only the case for the persons with dementia, but also for the proxies. We have had family members underestimating their loved ones in using cutlery or overestimating the role of the person with dementia in household keeping for example.

These confabulations and over- or underestimations make it hard for designers to understand the situation at hand and to estimate how reliable a statement is. In one of our PD sessions a family member indicated that the preparation of a meal was problematic for his mother. He could not trust her to cut groceries even though she used to be a cook in her active life. According to the son, she would throw away too much of fine vegetables. In a follow-up session however, we observed that both had different standards in what can be considered as waste or not: while he complained her prodigality, she just used the 'better' part of the vegetables.

\section{PD may be too stressful for the person with dementia}

In their work on PD Grönvall \& Kyng (2013) indicated the difficulty in working with ill and weak users who have fewer resources left to participate in design and research settings. The same was felt in our studies when working with people with dementia: in both projects we had users who stopped participating: they felt too weak to continue or their partner turned ill or had to be hospitalized. Besides this, we experienced that most of our users participated in a PD session "to do us a favor" or as a favor to their loved ones.

\section{The differences between the designer and the person to design for are too big to speak about equality in participation}

A central element in participatory design is the blurring of the borders of the designer and the end-user as the latter becomes an active user (from design recipient to design decision-maker) (Binder, 1996; Luck, 2003). Additionally, a form of shared practice and shared agency (Light \& Luckin, 2008) between users and designers is noted. In the process of participation, (the aspiration of) equality (Luck, 2003; Muller, et al., 1993), mutual learning (Kensing \& Blomberg, 1998) and reciprocity and a transcendence of the users' own practice (Bødker \& Iversen, 2002) are of importance as well.

In working with people with dementia many of these aspirations of PD seem infeasible. The inability to learn new methods, rituals or tools (jwatson, 2011) makes transcending one's own practices a hard thing to do. In this way, we can also say that we, as designers and researchers learned a lot from the persons with dementia, but if the same is true the other way around, is hard to tell. In general, the question of equality seems to be not the case: to say it in a provocative way, no equality is gained, there is always a power relation which can not be changed by using PD practices.

6. The process of PD can be a burden for the designer In more than one occasion the design and research team was asked by family members or persons with dementia to give advice or aid in elements which are beyond the goal of the project or their role ("We have problems with our telco, who do you think we should call?"; "What type of medicine do you think others take?"). It is evident that a 'professional' attitude requires a sort of neutrality towards this type of situations.

In relation to this, the question of the emotional impact on researchers and designers has to be raised. The nature of most PD sessions demands to create a bond with your user that can result in an emotional burden during or after the project. Researchers and designers are working in situations that demand a high level of delicacy and are confronted with people who are in constant cognitive (and physical) decline. Quite some work has been done on ethical considerations in working with people with dementia (Dresser, 2000). However, little attention is given to the impact on the researcher or the designer.

\section{Minimal utterances are given too much importance} In one occasion we found ourselves sitting in a $60 \mathrm{~s}$ interior with a couple of whom the woman suffered from a severe form of dementia. Her participation was limited to big smiles and nods. Unexpectedly she declared that she was keen on wearing beautiful clothes and matching jewelry. This was confirmed by her husband saying that "clothes are very important to her, unlike us men" (focusing on the male researcher present). When analyzing the PD session it was this utterance we used to develop a concept for an intelligent wardrobe, aiding the partner in finding the correct clothes (matching weather forecasts and based on this woman's clothing style). While the concept of such an intelligent wardrobe might be beneficial to this couple (and others), the question is more whether this was really what this couple needed: didn't we extrapolate this one "saying" to much larger proportions? The tendency to do this is also described by Lindsay, Jackson, et al. (2012) on working with elderly: minimal utterances both verbal or visual are given too wide an importance.

\section{FUTURE WORK}

In our future work we will start from the premise that no general passe-partout participatory method of working with people with dementia can be found. This comes amongst others from the idea that the way in which dementia occurs and affects daily life is different for each person and thus, the method used will also be. We will describe in depth cases of the individualized 'configuring of participation' (Vines et al. 2013) we undertook in our Dementia Lab project. By sharing so-called method stories (detailed descriptions of the research in practice Lee, 2013) we will focus on not abstracting generic rules for method creation (or adaptation), but instead share the context, the application and adaptation of a method in use in a specific context. In doing so, we hope to stimulate 
designers and researchers in critically reflecting upon their own methods in working in a participatory manner with people with dementia.

\section{ACKNOWLEDGMENTS}

The Iminds-project ATOM was funded by the Flemish Government with support of IWT. Companies and organizations involved: Televic Health, GS1 Belgilux, WZC Sint-Jozef, KHLimburg, Pyxima, Broeders Alexianen. Research in the Dementia Lab was financed by the Flemish Government - Dep. of Economics, Science \& Innovation (Social Innovation call).

\section{REFERENCES}

American Psychiatric Association. (2000). Diagnostic and statistical manual of mental disorders: DSM-IV$T R \circledR$. American Psychiatric Pub.

Binder, T. (1996). Learning and knowing with artifacts: An interview with Donald A. Schön. AI \& SOCIETY, 10(1), 51-57. doi:10.1007/BF02716754

Bødker, S., \& Iversen, O. S. (2002). Staging a professional participatory design practice: moving PD beyond the initial fascination of user involvement (pp. 11-18). Proc. of the second Nordic conference on Human-computer interaction, ACM.

Dresser, R. (2000). Dementia research: Ethics and policy for the twenty-first century. Ga. L. Rev., 35, 661.

Grönvall, E., \& Kyng, M. (2011). Beyond Utopia: reflections on participatory design in home-based healthcare with weak users (pp. 189-196). Proc. of the 29th Annual European Conference on Cognitive Ergonomics, ACM.

Grönvall, E., \& Kyng, M. (2013). On participatory design of home-based healthcare. Cognition, Technology \& Work, 15(4), 389-401.

Holbø, K., Bøthun, S., \& Dahl, Y. (2013). Safe walking technology for people with dementia: what do they want? (p. 21). Proc. of the 15th International ACM SIGACCESS Conference on Computers and Accessibility, ACM.

Jones, C. A., \& Arning, B. (2006). Sensorium: embodied experience, technology, and contemporary art. MIT Press.

jwatson. (2011, August 17). Alzheimer's Disease Fact Sheet. National Institute on Aging. Text. Retrieved February 27, 2014, from http:/www.nia.nih.gov/alzheimers/publication/alzheimers -disease-fact-sheet

Kensing, F., \& Blomberg, J. (1998). Participatory design: Issues and concerns. Computer Supported Cooperative Work (CSCW), 7(3-4), 167-185.

Kitwood, T. (1997). Dementia reconsidered: The person comes first. Philadelphia.

Lee, J.-J. (2013). Method-making as a method of designing. In Proceedings from the 5th Nordic Design Research Conference, Nordes 2013. Copenhagen, Denmark.
Lewis, J., \& Ritchie, J. (2003). Generalising from qualitative research. Qualitative Research Practice: A Guide for Social Science Students and Researchers, 263286.

Light, A., \& Luckin, R. (2008). Designing for social justice: people, technology, learning.

Lindsay, S., Brittain, K., Jackson, D., Ladha, C., Ladha, K., \& Olivier, P. (2012). Empathy, participatory design and people with dementia (pp. 521-530). Proc. of the 2012 ACM ann. conference on Human Factors in Computing Systems, ACM.

Lindsay, S., Jackson, D., Schofield, G., \& Olivier, P. (2012). Engaging older people using participatory design (pp. 1199-1208). Proc. of the 2012 ACM ann. conference on Human Factors in Computing Systems, ACM.

Lobo, A., Launer, L., Fratiglioni, L., Andersen, K., Di Carlo, A., Breteler, M., ... Martinez-Lage, J. (1999). Prevalence of dementia and major subtypes in Europe: A collaborative study of population-based cohorts. Neurologic Diseases in the Elderly Research Group. Neurology, 54(11 Suppl 5), S4-9.

Luck, R. (2003). Dialogue in participatory design. Design Studies, 24(6), 523-535.

Mayer, J. M., \& Zach, J. (2013). Lessons learned from participatory design with and for people with dementia (pp. 540-545). Proc. of the 15th international conference on Human-computer interaction with mobile devices and services, ACM.

Meiland, F. J., Bouman, A. I., Sävenstedt, S., Bentvelzen, S., Davies, R. J., Mulvenna, M. D., ... Bengtsson, J. E. (2012). Usability of a new electronic assistive device for community-dwelling persons with mild dementia. Aging \& Mental Health, 16(5), 584-591.

Miller, J. (1990, April 15). Goodbye to all this. Independent on Sunday, pp. 3-5.

Muller, M. J., Wildman, D. M., \& White, E. A. (1993). "Equal opportunity" PD using PICTIVE. Communications of the ACM, 36(6), 64.

Ponterotto, J. G. (2006). Brief note on the origins, evolution, and meaning of the qualitative research concept "thick description." The Qualitative Report, 11(3), 538-549.

Schepers, S. (2013). MAP-it. The Art of Designing a Participatory Mapping Method. Knowing (by) Designing., 1(1), 275-281.

Span, M., Hettinga, M., Vernooij-Dassen, M., Eefsting, J., \& Smits, C. (2013). Involving people with dementia in the development of supportive IT applications: A systematic review. Ageing Research Reviews, 12(2), 535551.

Vines, J., Clarke, R., Wright, P., McCarthy, J., \& Olivier, P. (2013). Configuring participation: on how we involve people in design (pp. 429-438). Proc. of the SIGCHI Conference on Human Factors in Computing Systems, ACM. 